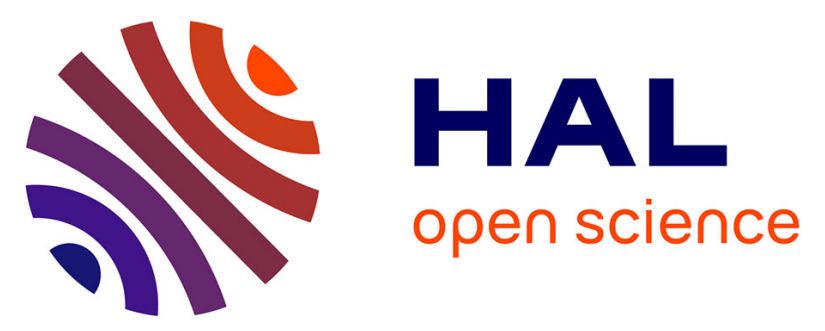

\title{
An Energy based approach of electromagnetism applied to adaptative meshing and error criteria
}

\author{
Dimitrios Ladas, V. Mazauric, Gérard Meunier, Olivier Chadebec, Marcel \\ Ebene Ebene, Yves Maréchal, Philippe Wendling
}

\section{To cite this version:}

Dimitrios Ladas, V. Mazauric, Gérard Meunier, Olivier Chadebec, Marcel Ebene Ebene, et al.. An Energy based approach of electromagnetism applied to adaptative meshing and error criteria. IEEE Transactions on Magnetics, 2008, 44 (6), pp.1246-1249. 10.1109/TMAG.2007.916656 . hal-00287868

\section{HAL Id: hal-00287868 https://hal.science/hal-00287868}

Submitted on 27 Jun 2008

HAL is a multi-disciplinary open access archive for the deposit and dissemination of scientific research documents, whether they are published or not. The documents may come from teaching and research institutions in France or abroad, or from public or private research centers.
L'archive ouverte pluridisciplinaire HAL, est destinée au dépôt et à la diffusion de documents scientifiques de niveau recherche, publiés ou non, émanant des établissements d'enseignement et de recherche français ou étrangers, des laboratoires publics ou privés. 


\title{
An Energy Based Approach of Electromagnetism Applied to Adaptive Meshing and Error Criteria
}

\author{
D. Ladas ${ }^{1}$, V. Mazauric ${ }^{1}$, G. Meunier ${ }^{2}$, O. Chadebec ${ }^{2}$, M. Ebene-Ebene ${ }^{2}$, Y. Maréchal ${ }^{2}$, and P. Wendling ${ }^{3}$ \\ ${ }^{1}$ Schneider Electric, Innovation Direction, 38050 Grenoble Cedex 9, France \\ ${ }^{2}$ G2ELAB, INPG-UJF-CNRS UMR 5269, 38402 Grenoble, France \\ ${ }^{3}$ MAGSOFT Corp., Ballston Spa, NY 12020 USA
}

\begin{abstract}
In order to improve the finite-element modeling of macroscopic eddy currents (associated with motion and/or a time-varying electrical excitation), an original error criterion for adaptive meshing, based on a local power conservation, is proposed. Then, the importance of the order element in the error computation is investigated. Finally, the criterion is coupled to a "bubble" mesh generator, and an adaptive meshing of a 2-D induction heating case is performed.
\end{abstract}

Index Terms-Adaptive meshing, eddy currents, error criterion, power conservation.

\section{INTRODUCTION}

$\mathbf{T}$ HE modeling of eddy currents represents a considerable stake for optimizing both performances and energy efficiency of electromechanical devices. In an eco-designing outlook, it is necessary to consolidate all the energies spent during the lifetime of a product, in order to achieve its life cycle assessment. The precision in calculations of energy quantities is then a crucial point. We propose to extend those energy considerations to the modeling of macroscopic eddy currents. At this scale, they are due to the movement of massive conductors and/or a time-varying electrical excitation. Currently, those phenomena are correctly modeled with the finite-element method (FEM) in 2-D, but in 3-D many problems remain. We focused on the massive conductor meshing, where the apparition of eddy currents implies a skin effect. The issue is to take account of the skin depth variations that occur especially in transient cases. The adaptive meshing technique is suitable to meet this purpose. Furthermore, from a user point of view, the FEM software needs to be easier to use and more reliable.

We used an energy-based approach of electromagnetism to define a general error criterion in conductors adapted to timevarying problems. The criterion is validated on a 2-D induction heating case. A demonstration of a whole remeshing process is finally shown to highlight the validity of the new error criterion.

\section{ENERGY-BASED APPROACH OF EleCtromagnetism}

\section{A. From Thermodynamics to FEM}

A recent work [1] has permitted to derive the Maxwell equations from thermodynamic considerations. Quasi-static laws of electromagnetism are deduced from experimental evidences, the electric charge conservation and variational principles derived from thermostatistics. While flux density divergence-free is obtained everywhere from the stationary condition on the

Digital Object Identifier 10.1109/TMAG.2007.916656

Color versions of one or more of the figures in this paper are available online at http://ieeexplore.ieee.org.
Gibbs' free energy, the Maxwell-Faraday equation is obtained, in conductors, through the minimization of the functional (1). This approach addresses a deeper justification of the FEM that consists in building an approximation of the variational formulations.

$$
\wp \text { Functional }=\int_{\text {Conductors }}\left(\rho \mathbf{j}^{2}+\frac{\partial(\mathbf{B H})}{\partial t}\right) d v
$$

where $\rho$ is the electric resistivity, $\mathbf{j}$ is the current density, $\mathbf{B}$ is the induction, and $\mathbf{H}$ is the magnetic field.

\section{B. Adaptive Meshing and Energy-Based Approaches}

Adaptive meshing has been well explored for magnetostatics cases. A complete technique, from error criterion to remeshing, is proposed in [2]. While the criterion used in the latter is classical, some papers have proposed energy-based approaches:

- in [3], a local error criterion based on the precision on the computation of the energy stored in each element;

- for magnetostatics cases with movement [4], focusing on the maximization of the co-energy functional;

- [5] proposes to evaluate the error on the behavior law, from the complementary variational principle, using the Ligurian.

Some papers have presented adaptive meshing techniques dedicated to eddy-current problems:

- [6] is an extension of [5] to eddy-current problems, still using complementary formulations;

- [7] proposes two error estimators, one based on the principle of the Ligurian and the other based on the numerical discontinuity of the field;

- [8] uses a local solution in the conducting region;

- [9] uses an error estimator based on the precision on the Mawxell-Ampère equation.

However, adaptive meshing is not widely spread for timevarying cases. The error criteria used are limited to continuity or geometric considerations, and they do not address any justification but local quality solution of the magnetic field. Here we propose a new point of view, in which the refinement will enforce a better conservation of power quantities. 


\section{ERror CRITERION FOR EDDY-CURRENT PROBLEMS}

\section{A. Definition}

The idea was to find a criterion suitable both for time-harmonic problems and for transient ones. To solve an eddy-current problem described by (2) (written in $\mathbf{H}$ formulation) in conducting regions with the FEM, the magnetic field $\mathbf{H}$ is obtained by writing the stationarity of the power functional (1) with respect to the field variations, projected on a mesh.

$$
\operatorname{curl} \rho \mathbf{c u r l H}-\frac{\partial \mu \mathbf{H}}{\partial t}=0
$$

where $\mu$ is the magnetic permeability of the conductor.

But for time-harmonic cases, (2) turned into its complex form cannot be transformed into a classical variational problem [10] and the solution is a saddle point obtained by writing the stationarity of the following complex functional:

$$
P_{\text {Complex }}=\int_{\text {Conductors }}\left(\rho \mathbf{j} \mathbf{j}^{*}+\mathbf{i} \omega \mu \mathbf{H H}^{*}\right) d v
$$

where $\mathbf{i}$ is the complex phasor, and $\omega$ is the excitation field frequency.

Consequently, the idea of a minimization of the power functional with regards to the node position cannot work. We move on to local error evaluation, with the idea that a good meshing has to secure energy quantities computations. In other words, the total power spent in an element has to be equal to the power supplied into it. The power spent in an element $\Omega_{\mathrm{i}}$ is due to Joule losses and magnetic power (4):

$$
P_{\text {Spent }}=\int_{\Omega_{i}}\left(\rho \mathbf{j}^{2}+\mathbf{H} \frac{\partial \mathbf{B}}{\partial t}\right) d v
$$

To evaluate the power supplied, we introduce Poynting's vector, which is mostly used in high-frequency problems. The power supplied in an element is equal to the flux of Poynting's vector through the border $\Gamma_{\mathrm{i}}$ of the element:

$$
P_{\text {Supplied }}=-\oint_{\Gamma_{i}}(\mathbf{E} \wedge \mathbf{H}) d s
$$

where $\mathbf{E}$ is the electric field.

The new error criterion proposed evaluates the local conservation of the power in each element:

$$
\begin{aligned}
\varepsilon_{\text {element } i} & =\left|P_{\text {Spent }}-P_{\text {Supplied }}\right|_{\text {elt }} \\
& =\left|\int_{\Omega_{i}}\left(\rho \mathbf{j}^{2}+\mathbf{H} \frac{\partial \mathbf{B}}{\partial t}\right) d v+\oint_{\Gamma_{i}}(\mathbf{E} \wedge \mathbf{H}) d s\right|
\end{aligned}
$$

After some calculation, using the Green theorem, the error reads:

$$
\varepsilon_{\text {element } i}=\left|\int_{\Omega_{i}}\left[\left(\operatorname{rot} \mathbf{E}+\frac{\partial \mathbf{B}}{\partial t}\right) \cdot \mathbf{H}-(\operatorname{rot} \mathbf{H}-\mathbf{j}) \cdot \mathbf{E}\right] d v\right|
$$

This error criterion is then adapted to mesh refinement in conducting regions. It is general and does not depend on the dimension, element order, geometric specificities, or magnetic formulation. According to the formulation, the criterion will not enforce the same properties.

- In $A-V$ formulations: the first term of (7) vanishes. The criterion evaluates the precision on the Maxwell-Ampère equation, leveled by the electric field. Apart from the energy aspect, this is close to classical criteria.

- In $T-\boldsymbol{\Phi}$ formulations, which are compliant to the thermodynamic approach of electromagnetism [1], the second term of (7) vanishes. This gives a stronger signification to the criterion because in that case, the criterion evaluates the precision on the Maxwell-Faraday equation, which is linked to induced effects. Furthermore, the error is leveled by the magnitude of the magnetic field $\mathbf{H}$, which is very suitable for eddy-current problems, because of the field-damping phenomenon.

This new error criterion is then robust and general enough to drive any remeshing technique.

\section{B. About the Importance of Element Order}

A classical way to evaluate the error is to check the precision on the equation weakly solved in the FEM resolution. Hence, the classical error criterion proposed is

$$
\underset{\substack{\text { Clessical } \\ \text { element } \mathrm{i}}}{=} \oint_{\Gamma_{i}} \mathbf{B} \cdot d s
$$

When we want to compute (5) or (8), we have two different solutions.

- Using the field in the neighbor elements, which means to evaluate the quantity exiting from the neighbors. This is the way classically used.

- Using the field in the considered element, in order to compute the quantity entering into the element.

For the latter, it is obvious that with first order elements, the approximation on the variables are not enough precise to give the expected result. It is then necessary to use the classical way. But with second order elements, we show that it is a relevant way to compute an error. Indeed the coupling between elements is intrinsic within the finite-element matrix, but it requires an approximation accurate enough, i.e., a high enough order. The advantages of this approach are twofold:

- Evaluating an error with this method allows to check the self-consistency of the quantity computed, which is suitable for the energy-based approach we propose with the criterion (6).

- From an algorithm point of view, recovering the neighbors and computing a quantity on them are CPU time costly, especially for problems with a large number of nodes.

As a drawback, the linear system is bigger with second order elements, but they are well-adapted for time-varying problems such as eddy currents.

We now introduce a 3-D time-harmonic induction heating case modeled thanks to Flux $($, which uses $T-\Phi$ formulations for 3 -D cases. All the error criteria are computed using the field in the element, without using the neighbors. 


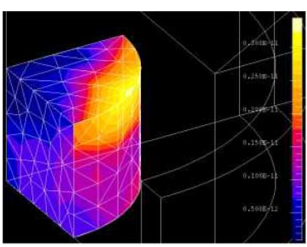

Energy-based criterion (6)

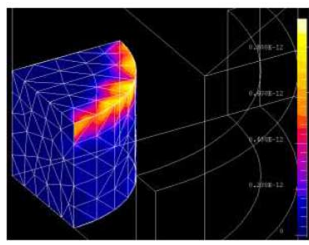

2nd

Order

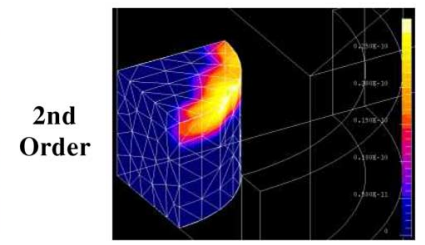

Fig. 1. Error cartography on the steel region for the 3-D induction heating case, with the energy-based criterion (left) and with the classical one (right). Whereas the criterion (6) points out the relevant regions whatever the order, the classical one (8) fails with first order elements.

TABLE I

Details About the Criteria ACCORDING to THE ElEMENT ORdER, Without USING THE NEIGHBORS IN THE COMPUTATION. WiTH FIRST ORDER ELEMENTS, ONLY THE ENERGY-BASED CRITERION IS RELEVANT. WITH SECOND ORDER ELEMENTS, BOTH INDICATE THE REGIONS WHICH NEED TO BE REFINED

\begin{tabular}{|c|c|l|}
\hline & $\begin{array}{l}\text { Energy-based } \\
\text { criterion }\end{array}$ & $\begin{array}{l}\text { Classical } \\
\text { criterion }\end{array}$ \\
\hline $\mathbf{1}^{\text {st }}$ order & $\varepsilon_{i}=\int_{\Omega_{i}}\left(\mathbf{H} \frac{\partial \mathbf{B}}{\partial t}\right) d v$ & $\begin{array}{c}\varepsilon_{i} \approx 0 \\
\text { (points out non relevant } \\
\text { regions for refinement) }\end{array}$ \\
\hline $\mathbf{2}^{\text {nd }}$ order & True error & True error \\
\hline
\end{tabular}

We can see on Fig. 1 the error cartography in the massive conductor (core), with different criteria and element order. These results are detailed in Table I. We want to insist on two points.

- With first order elements, we cannot compute a real error, which implies that (8) highlights irrelevant regions.

- Equation (6) is equal to the magnetic power with first order element. This is not a real error, however we can see that the region highlighted are coherent with the second order results. Hence, the criterion (6) is not meaningless even with first order element, and we can find such considerations in [11].

\section{ApPlication to a 2-D AdAPtive Meshing Process}

\section{A. The "Bubble" Mesh Generator}

The criterion proposed in this paper is able to drive any remeshing technique. However, to have a powerful adaptive meshing process, it is necessary for the mesh generator to ensure good quality elements. To take advantage of the robustness of our criterion, a coupling with the bubble-meshing technique [12] is proposed. This is a physics-based approach of meshing: from a given mesh, nodes are associated with air bubbles and with a thermostatistics interaction law, they are moved to reach a more stable state. The node density is specified thanks to the error criterion. The mesh resulting from this technique has more good quality element than the first one resulting from a Delaunay triangulation, for instance. The criterion allows to build an error map that can drive the bubble mesh generator.
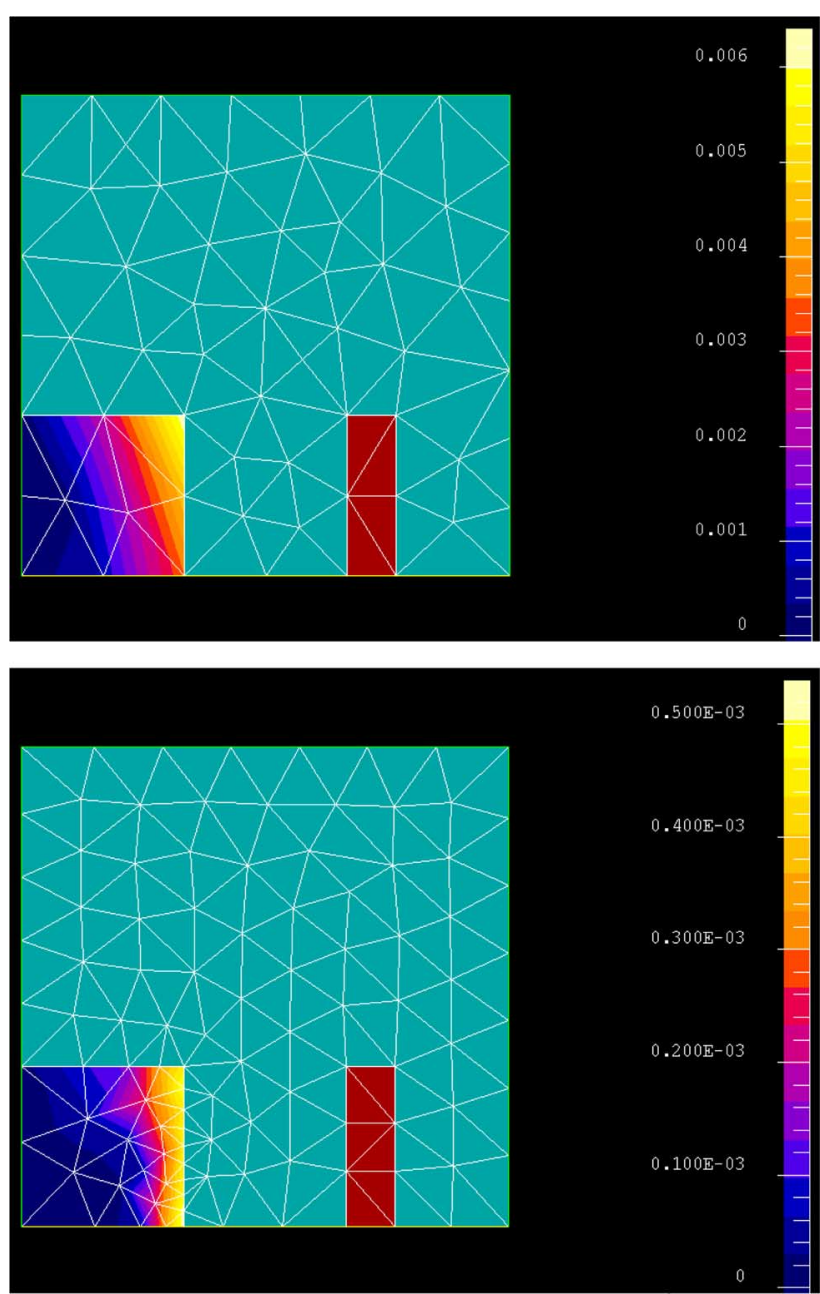

Fig. 2. 2-D induction heating case modeled with Flux@. Error with the criterion (6) in the conducting region for the first mesh (top) and for the refined one (bottom). The local error is divided by 10 . The mesh is refined in the conducting region to match the skin effect, and a regularization is performed in the air thanks to the bubble mesh generator.

TABLE II

Comparison Between Global POWER QuANTITIES ON DIFFERENT Meshes

\begin{tabular}{|l|c|c|c|c|}
\hline & $\begin{array}{l}\text { Reference } \\
\text { (fine mesh) }\end{array}$ & $\begin{array}{l}\text { Starting } \\
\text { mesh } \\
(64 \text { nodes })\end{array}$ & $\begin{array}{l}\text { Refined } \\
\text { mesh } \\
(110 \text { nodes })\end{array}$ & $\begin{array}{l}\text { Uniform } \\
\text { mesh } \\
(110 \\
\text { nodes })\end{array}$ \\
\hline Pj & $0.0070 \mathrm{~W}$ & $0.017 \mathrm{~W}$ & $0.0082 \mathrm{~W}$ & $0.012 \mathrm{~W}$ \\
\hline Dev. & & $\mathbf{1 4 2} \%$ & $\mathbf{1 7} \%$ & $\mathbf{7 1} \%$ \\
\hline Pmag & $0.0064 \mathrm{~W}$ & $0.0031 \mathrm{~W}$ & $0.0052 \mathrm{~W}$ & $0.0034 \mathrm{~W}$ \\
\hline Dev. & & $\mathbf{5 2} \%$ & $\mathbf{1 9} \%$ & $\mathbf{4 7} \%$ \\
\hline
\end{tabular}

\section{B. Adaptive Meshing With the Mesh Generator and the Energy-Based Error Criterion}

A 2-D induction heating case is modeled with Flux (․

The mesh is adapted using the error criterion (6) in the conducting region. After few iterations, the local error decreased (Fig. 2) and the global power quantities convergence is ensured. With the same number of nodes we ensure a better precision both on the Joule losses and on the magnetic power (Table II). The error is still high, but the remeshing process can be iterated to improve the results. As the process is not yet optimized, it is difficult to benchmark it fairly. 


\section{About Remeshing Strategies}

The strategy exposed in this work consists in:

- evaluating the error in the conducting region;

- remeshing this region;

- regularization of the mesh in air region, without evaluating any error. This step is done automatically thanks to the "bubble" mesh generator.

The next step of this work will be to consider other solutions, where an error criterion is defined in the air (magnetostatic criterion) and the mesh refined according to this new information. Hence, the problem concerning the borders between the different regions has to be considered.

\section{CONCLUSION}

We proposed an original energy-based error criterion for adaptive meshing applied to eddy-current problems. It allows to remesh conductors in order to adapt the discretization to the skin effect. As it is general, it can be used in any adaptive meshing procedure. Some elements about the importance of element order on the computation of error criteria have been given. Especially, we pointed out that the new error criterion works whatever the order, without the need of using the neighbor elements, and that second order elements allow to compute an error without evaluating a numerical discontinuity. The criterion was coupled to a "bubble" mesh generator to perform an adaptive meshing of a 2-D induction heating case, in order to validate its reliability. The criterion can easily be used for 3-D cases. The limitation concerns the mesh generator. Improvements on the "bubble" mesh generator are in progress, in order to evaluate the whole method on 3-D cases.

With robust modeling methodology, based on energy considerations, it is possible to carry out an optimization focused on energy efficiency of devices, avoiding pollution transfers. The next step of this work is the extension into 3-D modeling and for transient cases.

\section{ACKNOWLEDGMENT}

This work was supported in part by the French Agency for Environment and Energy Management (ADEME) under the Grants-in-Aid for sustainable development \#0407C0030 and \#0407C0061.

\section{REFERENCES}

[1] V. Mazauric, "From thermostatistics to Maxwell's equations: A variational approach of electromagnetism," IEEE Trans. Magn., vol. 40, no. 2, pp. 945-948, Mar. 2004.

[2] L. Jänicke and A. Kost, "Error estimation and adaptive mesh generation in the 2D and 3D finite element method," IEEE Trans. Magn., vol. 32, no. 3, pp. 1334-1337, May 2004.

[3] A. R. Pinchuk and P. P. Silvester, "Error estimation for automatic adaptive finite element mesh," IEEE Trans. Magn., vol. MAG-21, no. 6, pp. 2551-2554, Nov. 1985.

[4] S. Dufour, G. Vinsard, and B. Laporte, "A 2D adaptive mesh with movement," IEEE Trans. Magn., vol. 37, no. 5, pp. 3482-85, Sep. 2001.

[5] J. Rikabi, C. F. Bryant, and E. M. Freeman, "Error-based approach to complementary formulations of static fields solutions," Int. J. Numer. Methods Eng., vol. 26, pp. 1963-1987, 1988.

[6] J. Rikabi, C. F. Bryant, and E. M. Freeman, "Error-based derivation of complementary formulations for the eddy-current problem," in IEE Proc., 1988, vol. 135, pp. 208-216.

[7] C. Li, Z. Ren, and A. Razek, "An approach to adaptive mesh refinement for three-dimensional eddy-current computations," IEEE. Trans. Magn., vol. 30, no. 1, pp. 3482-3485, Jan. 1994.

[8] S. Dufour, G. Vinsard, and B. Laporte, "Mesh improvement in 2-D eddy-current problems," IEEE Trans. Magn., vol. 38, no. 2, pp. 377-380, Mar. 2002.

[9] O. Sterz, A. Hauser, and G. Wittum, "Adaptive local multigrid methods for solving time-harmonic eddy-currents problems," IEEE Trans. Magn., vol. 42, no. 2, pp. 309-318, Mar. 2006.

[10] A. Bossavit, "Eddy-current problems," in Computational Electromagnetism: Variational Formulations, Complementarity, Edge Elements. San Diego, CA: Academic, 1998, pp. 219-246.

[11] D. P. Labridis, "Comparative presentation of criteria for adaptative finite-element mesh generation in multiconductor eddy-current problems," IEEE Trans. Magn., vol. 36, no. 1, pp. 267-280, Jan. 2000.

[12] K. Shimada and D. C. Gossard, "Automatic triangular mesh generation of trimmed parametric surfaces for finite element analysis," Computer Aided Geometric Design, vol. 15, pp. 199-222, 1998.

Manuscript received June 24, 2007. Corresponding author: D. Ladas (e-mail: dimitrios.ladas@schneider-electric.com). 